\title{
Comprehending Telemedicine: An Online Survey amidst COVID-19 Pandemic
}

\author{
Prabhat K Agrawal $^{1}$, Nikhil Pursnani ${ }^{2}$, Akhil P Singh ${ }^{3}$, Boentika Singh ${ }^{4}$, Ashish Gautam ${ }^{5}$, Ruchika Garg ${ }^{6}$
}

\begin{abstract}
Introduction: In pre-COVID era, telemedicine was not widely accepted for patient care and management. In COVID-19 pandemic, due to strict social distancing and various government guidelines laid down for patient management and care, it has been widely accepted.

Methods: We did an online survey from June 20 to July 20, 2020, to find out acceptance and knowledge of telemedicine among clinicians of India for patient care.

Results: Earlier only $11 \%$ of clinicians were using telemedicine, due to strict social distancing there has been a surge; now $57 \%$ of clinicians have accepted it. Analytical data also showed that after this pandemic $69 \%$ of clinicians will still continue to use telemedicine.

Discussion: With telemedicine we can easily solve complaints of patients in outdoor department and quarantine center, as well as provide psychological counseling of COVID-19 and non-COVID-19 patients.

Keywords: COVID-19 pandemic, Lockdown, Online consultation, Teleconsultation, Telemedicine.

Journal of South Asian Federation of Obstetrics and Gynaecology (2020): 10.5005/jp-journals-10006-1832
\end{abstract}

\section{INTRODUCTION}

During lockdown and post-lockdown many private hospitals, government hospitals, and clinicians have adapted to telemedicine. The surge in teleconsultation follows the guidelines which are recently formed and issued by Ministry of Health and Family Welfare in collaboration with NITI Aayog and Board of Governors, Medical Council of India (MCl) on March 25, 2020. In this COVID19 pandemic, this helps the clinician to use this new method of patient consultation with ease because many clinicians have lost their precious life due to undue exposure to virus during OPD consultations. During disaster and pandemic, it is very challenging to provide facilities. Though telemedicine will not solve all problems, it is very well suited in this time where medical practitioners can evaluate and manage their patients. Teleconsultation can be done without exposing staff to viral/other infections in the time of such outbreak. If patient uses teleconsultation, he/she can save his/ her time and money to visit clinician chamber/hospital. Amid this pandemic, the guidelines were issued to smoothen the healthcare facility as clinician can give consultation to patient remotely which would protect the doctors and patients from catching infection and does not break the rules of lockdown.

The guidelines which were laid down by $\mathrm{MCl}$ involve all digital channels of communication with the patient that leverage information on digital technology platforms including voice, audio, text, and digital data exchange. Above all, doctor is allowed to prescribe treatment as well as maintain patients clinical records digitally, which can be assessed at any remote place as well. Unill now many platforms are introduced for the teleconsultation like Practo, Lybrate, Healthplix, etc. Teleconsultation still has not been widely used by Indian medical practitioners. Teleconsultation can be difficult to elderly and uneducated patients who are low on technical skills for navigating on digital consultation platforms. Due to easy availability of smart phones, teleconsultation can be used with simplicity on chatting/video apps like Facebook messenger and WhatsApp. We did an online survey among the clinicians to

\footnotetext{
1,2,5 PG Department of Medicine, SN Medical College, Agra, Uttar Pradesh, India

${ }^{3}$ Department of ENT, SN Medical College, Agra, Uttar Pradesh, India

${ }^{4}$ SN Medical College, Agra, Uttar Pradesh, India

${ }^{6} \mathrm{PG}$ Department of Obstetrics and Gynecology, SN Medical College,
} Agra, Uttar Pradesh, India

Corresponding Author: Ashish Gautam, PG Department of Medicine, SN Medical College, Agra, Uttar Pradesh, India, Phone: +91 9927089665, e-mail: dr_ashishgautam@yahoo.co.in

How to cite this article: Agrawal PK, Pursnani N, Singh AP, et al. Comprehending Telemedicine: An Online Survey amidst COVID-19 Pandemic. J South Asian Feder Obst Gynae 2020;12(6):345-347.

Source of support: Nil

Conflict of interest: None

see their knowledge regarding teleconsultation in the times like COVID-19 pandemic and lockdown.

\section{Material and Methods}

This online survey was done from June 20 to July 20, 2020. Selfadministered questionnaire was developed and shared with clinicians via email and social media platforms like Facebook and WhatsApp. This questionnaire consisted of two parts including demographic information and knowledge about teleconsultation. All the participants signed the digital informed consent form. All information from clinicians was kept secured and anonymous. A total of 344 participants filled this online questionnaire.

\section{Results}

An online survey was done from June 20 to July 20, 2020, responses of 344 participants were recorded. With the recorded responses, it is clear that due to COVID-19 pandemic telemedicine is a boon for 
Table 1: Showing responses of participants

\begin{tabular}{|c|c|c|c|}
\hline \multirow[b]{2}{*}{ SI. No. } & \multirow[b]{2}{*}{ Questions } & \multicolumn{2}{|c|}{ Responses } \\
\hline & & Yes & No \\
\hline 1 & Are you using telemedicine? & $196(57 \%)$ & $148(43 \%)$ \\
\hline 2 & $\begin{array}{l}\text { Are you aware about recent } \\
\text { guidelines given by } \mathrm{MCl} \text { related to } \\
\text { telemedicine in India? }\end{array}$ & $230(67 \%)$ & $114(33 \%)$ \\
\hline 3 & $\begin{array}{l}\text { Are you aware that fee can be } \\
\text { charged for online consultation/ } \\
\text { teleconsultation? }\end{array}$ & $296(86 \%)$ & $48(14 \%)$ \\
\hline 4 & $\begin{array}{l}\text { Do you know that prescriptions } \\
\text { given after teleconsultation are } \\
\text { medicolegally valid? }\end{array}$ & $282(81 \%)$ & $62(19 \%)$ \\
\hline 5 & $\begin{array}{l}\text { Are you aware about record-keeping } \\
\text { in telemedicine? }\end{array}$ & $238(69 \%)$ & $106(41 \%)$ \\
\hline 6 & $\begin{array}{l}\text { Were you using telemedicine before } \\
\text { corona pandemic? }\end{array}$ & $38(11 \%)$ & $306(89 \%)$ \\
\hline 7 & $\begin{array}{l}\text { Do you know that some health } \\
\text { insurance plans cover telemedicine } \\
\text { costs? }\end{array}$ & $92(27 \%)$ & $252(73 \%)$ \\
\hline 8 & $\begin{array}{l}\text { Do you think various telemedicine } \\
\text { applications available online are } \\
\text { keeping patient data private and } \\
\text { secure? }\end{array}$ & $192(56 \%)$ & $152(44 \%)$ \\
\hline 9 & $\begin{array}{l}\text { Will you continue using } \\
\text { telemedicine once the corona } \\
\text { pandemic is controlled? }\end{array}$ & $236(69 \%)$ & $108(31 \%)$ \\
\hline
\end{tabular}

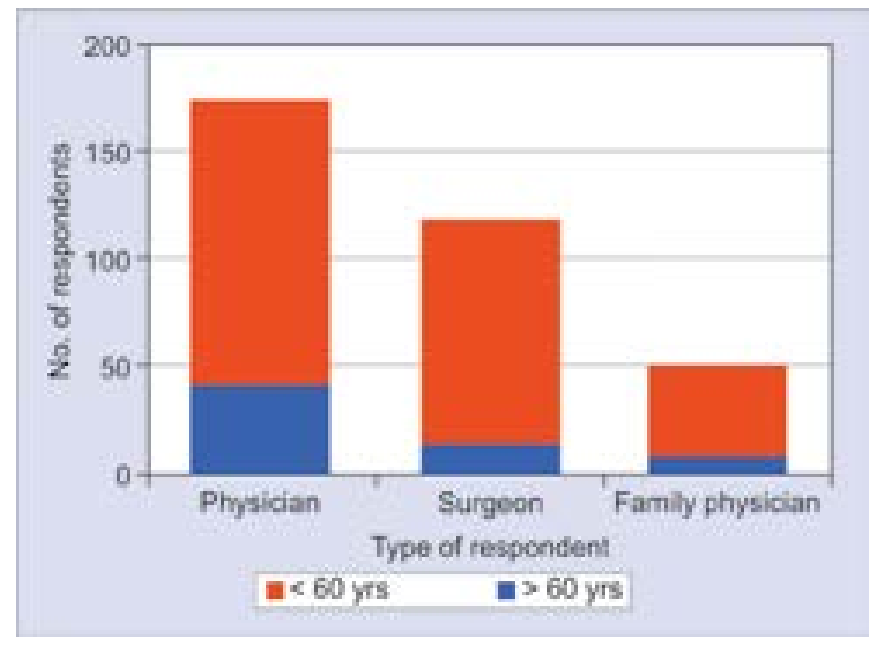

Fig. 1: Distribution of participants according to their age and specialties

patients as well as doctors and healthcare workers in such a crucial time (Table 1). Patients now can connect to their doctor while sitting remotely at their home/office. Out of total participants, 50\% (174/344) were physicians/allied branches, 35\% (120/344) were surgeon/allied branches, and the rest 15\% (50/344) were family physicians. Majority of the doctors, $81 \%$ (280/344), who participated in the survey were less than 60 years of age and rest $19 \%(64 / 344)$ were aged 60 years or more. The data recorded show that $57 \%$ (196/344) of the doctors (family physician, surgeon/ physician, and its allied branches) are currently using telemedicine (Fig. 1).

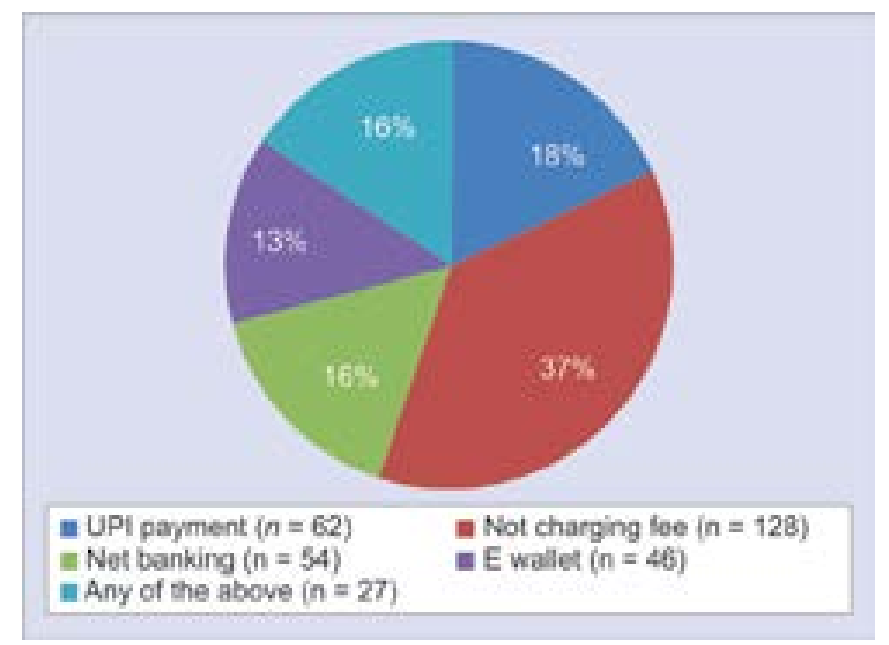

Fig. 2: Distribution of mode of payment for teleconsultation

The responses show that $67 \%$ (230/344) of participants were aware about the recent guidelines given by $\mathrm{MCl}$ on telemedicine practice in India, while 33\% (114/344) were not. Majority of $86 \%(296 / 344)$ were aware that a fee can be charged for online consultation/teleconsultation just like regular visits to hospitals while only $14 \%$ (48/344) were not. Sixty-five percent (224/344) of the doctors were charging fees through different modes (UPI, e-wallet, and Net banking), while 35\% (120/344) of the clinicians were not charging consultation fee. A total of $82 \%$ (282/344) of participants knew that prescriptions given after teleconsultation are medicolegally valid while $18 \%(62 / 344)$ of participants do not know (Fig. 2). A total of $69 \%$ (238/344) of participants knew and were aware about record keeping in telemedicine is must whereas 31\% (106/344) did not know. Both patients and the doctors are switching over to telemedicine/teleconsultation, due to fear of getting infected with nCOVID-19 virus during their visit to doctor clinic/hospital. Only $26 \%$ (92/344) of participants knew that some health insurance plans cover telemedicine costs while 74\% (252/344) did not know. Fifty-five percent (192/344) of doctors thought that telemedicine applications available online are keeping patient data private and secure while 45\% (152/344) did not agree to this. Before the world was ta ken over by COVID19 pandemic, only $11 \%$ of clinicians (family physician, surgeon/ physician, and its allied branches) were using telemedicine to provide health care to patients while $89 \%(306 / 344)$ were not. Now during COVID-19 pandemic and lockdown, 57\% of the clinicians are using telemedicine. Most of the doctors thought that telemedicine/ teleconsultation is important and is essential as shared by both age groups participant doctors, i.e., 69\% (236/344) of the clinicians said that they would adopt the practice of telemedicine even after the corona pandemic is over while only $31 \%(108 / 344)$ said that they will discontinue telemedicine practice. It was observed that most of the clinicians and patients choose WhatsApp as the easiest mode for teleconsultation.

\section{Discussion}

Telemedicine is practice of diagnosis, healthcare services, evaluation and research, and treatment of patients by using means of telecommunications technology and the provision of tangible healthcare to the patients, low-income regions, and distant places. ${ }^{1}$ 
Telemedicine cannot be a solution to the diseases that need hands-on treatment/surgeries but can definitely help in decreasing the burden of the healthcare system to a large stretch. Factors like advancement in wireless broadband technology, cell phones, and internet plays an important role in communication and connectivity. ${ }^{2}$ Because of these advances in technology, patient's clinical history details, videos, investigations, medical images like $X$-rays/scans, and real-time audio and video consultations became a reality. ${ }^{3}$ The modern day telemedicine requires patient and the doctor to own communicating devices. Devices like smartphone cameras and wearable biosensor also aid the doctor. With advances in tech industry, wearable watches can detect heart rates, calories, and sleep patterns, and can also detect a fall. These can be of help in gathering clinical data, which makes it easy to use without special training. ${ }^{3}$ Telemedicine practice reduces travel expenses, saves time, avoids crowd gathering, and reduces medical costs. It is easily accessible to the common people for consulting specialist doctors without disrupting their daily duties. It benefits healthcare providers by decreasing the load of patients from missed appointments and cancellations. ${ }^{4}$ Telemedicine is slowly migrating health care delivery system from hospitals/clinics into homes, both nationally and internationally. ${ }^{5}$ With the emergence of telemedicine, distance is no longer a barrier in providing health care to remote areas. ${ }^{6,7}$ Gujarat Government's e-health scheme, ${ }^{8}$ concept of village resource centers by ISRO, ${ }^{9}$ Jio Health Hub Application ,e-Sanjeevani OPD running in various states are few examples of India's steps toward pioneering in telemedicine. Telemedicine is a tool that allows clinician-toclinician/clinician-to-patient interaction to work up a case. Patients can use this to avail services of routine follow up, wound care, medication management, mental health appointments, second opinions, and addiction counseling by any registered medical practitioner. Telemedicine may be associated with a lot of ethical concerns related to security and confidentiality of patient data. ${ }^{10}$ This is the first study/online survey regarding knowledge and attitude of clinicians about telemedicine/teleconsultation.

In the following survey conducted, there is a surge in number of doctors using telemedicine due to the lockdown in corona crisis. Compared to pre-COVID-19 pandemic era, only $11 \%$ of clinicians were using telemedicine but now $57 \%$ of clinicians are using it. Due to COVID-19 pandemic and lockdown, outdoor practice of clinicians has changed a lot. Sixty-nine percent of the doctors will continue with the telemedicine/teleconsultation practice even after this pandemic is under control. At our institute S.N. Medical College, Agra, we started first time teleconsultation during lockdown and we received 4,498 calls from April 29 to June 30, 2020, for different departments' consultation.

\section{Conclusion}

Telemedicine has become a booming necessity. During COVID-19 pandemic, pros of using it outweigh the cons that come along with it. Lack of awareness and poor acceptance of new technology by the public is a major challenge that needs to be overcome. Governments are now starting to take a keen interest in developing telemedicine practices like e-Sanjeevani OPD, resulting in a steady rise of its utilization in public health. A fair number of doctors have knowledge toward telemedicine. Practicing physicians and residents can be made aware about telemedicine and issues related to its use by various workshops to provide necessary telemedicine/ teleconsultations to the people in need at times like these.

\section{ACKNOWLedgment}

None.

Statement of ethics: Ethics approval was taken. Ref no: CARE/ EC/2020-05.

Author contributions: The study design was formed by Dr. Prabhat Kumar Agrawal, Data collection was done by Dr. Nikhil Pursnani and Dr. Akhil Pratap, Data analysis by Dr. Ashish Gautam, Proofreading and discussion was done by Dr Ruchika Garg and Boentika Singh.

\section{References}

1. Chellaiyan VG, Nirupama AY, Taneja N. Telemedicine in India: where do we stand? J Family Med Prim Care 2019;8(6):1872-1876. DOI: 10.4103/ jfmpc.jfmpc_264_19.

2. Serper M, Volk ML. Current and future applications of telemedicine to optimize the delivery of care in chronic liver disease. Clin Gastroenterol Hepatol 2018;16(2):157-161.e8. DOI: 10.1016/j. cgh.2017.10.004.

3. History of telemedicine; 2015 . Available from: http://mdportal.com/ education/history-of-telemedicine/ [accessed 24/07/2020].

4. Limor W. Telemedicine Trends to Watch in 2018; January 18, 2018. Available from: https://telemedicine.arizona.edu/blog/telemedicinetrends-watch-2018.

5. Chen P, Xiao L, Gou Z, et al. Telehealth attitudes and use among medical professionals, medical students and patients in China: a cross-sectional survey. Int J Med Inform 2017;108:13-21. DOI: 10.1016/j. ijmedinf.2017.09.009.

6. Mehta KG, Chavda P. Telemedicine: a boon and the promise to rural India. J Rev Prog 2013;1(6):1-3.

7. AMD Global Telemedicine. Telemedicine applications. Available from: https://www.amdtelemedicine.com/telemedicine-resources/ telemedicine-applications.html.

8. Kumar A, Ahmad S. A review study on utilization of telemedicine and e-Health services in public health. Asian Pacific J Heal Sci 2015;2(1):60-68.

9. Mishra SK, Singh IP, Chand RD. Current status of telemedicine network in India and future perspective. Proc Asia-Pacific Adv Network 2012;32:151-163. DOI: 10.7125/APAN.32.19.

10. Zayapragassarazan Z, Kumar S. Awareness, knowledge, attitude and skills of telemedicine among health professional faculty working in teaching hospitals. J Clin Diagn Res 2016;10(3):JC01-JC04. DOI: 10.7860/JCDR/2016/19080.7431. 